\title{
DOES THE ADMINISTRATION OF THE ANTERIOR LOBE OF THE HYPOPHYSIS TO THE TADPOLE PRO- DUCE AN EFFECT SIMILAR TO THAT OBTAINED FROM THYROID FEEDING?*
}

\section{PHILIP E. SMITH AND GARNETT CHENEY \\ Department of Anatomy, University of California BERKELEY}

In a recent paper Hoskins and Huskins $(1920)^{1}$ have advanced evidence showing that the feeding of the anterior lobe of. the pituitary gives an effect similar to, and perhaps even identical with, that which is characteristic for the administration of thyroid gland. This is the most convincing evidence which to our knowledge has been advanced in support of the hypothesis that the pituitary can act vicariously for the thyroid. Hoskins and Hoskins, in brief, showed that a preparation of the anterior lobe ${ }^{2}$ when fed to the tadpole gave the typical responses resulting from thyroid administration, i. e., cutaneous and mouth changes, leg growth, tail absorption, and other changes leading to metamorphosis. In the normal unoperated tadpole metamorphosis was prematurely inaugurated or greatly accelerated; in the thyroidectomized tadpole similar changes were induced, though, as is well known, they would never have otherwise appeared in these thyroidless specimens.

These results furthermore might appear to be partially though not completely in harmony with the findings obtained from the opposite procedure, namely, the ablation of the hypophysis. For, in the mammal, hypophyseal deficiency causes a retention of infantile characteristics, and in the tadpole the loss of the buccal component of the hypophysis results in the retention of the larval condition for the life of the individual. The opposite picture resulted from the feeding experiments of the Hoskins, namely a hastening of development, this presum-

*Aided by a grant from the Research Board of the University of California.

1. This paper appeared subsequentiy to the untimely death of Dr. Hoskins, by which experimental research in this field has lost a devoted contributor.

2. Anterior lobe tablets prepared by Armour and Company. 
ably being due to the presence of an excess of the pituitary secretion in the organism. It might thus appear that the results obtained by the Hoskins could logically be expected, for if the loss of the pituitary inhibits metamorphosis, should not the feeding of this substance accelerate it?

Yet it must be kept in mind that the retention of the larval condition in the hypophysectomized tadpole undoubtedly is not. a pure hypophyseal effect. Rather it is polyglandular in nature, for it has been known since Adler's experiments in 1914 that the loss of the pituitary leads to a profound atrophy or underdevelopment of the thyroid, findings which have been amply confirmed in a series of papers by Allen and Smith, while one of us (Smith, 1920) has shown that both components of the adrenal, the parathyroid glands, and the neural lobe of the hypophysis are profoundly affected by hypophysectomy. Of this system of organs, because of the well known metamorphic stimulus afforded by thyroid feeding in amphibia, (Gudernatsch, 1914 ; Lenhart, 1915 ; Morse, 1914 ; 'and others) it seems reasonable to refer the immediate fault for the failure of the hypophysis-free tadpole to metamorphose more to the atrophy or underdevelopment of the thyroid than to an hypophyseal deficiency.

It thus seems that we may justly implicate the thyroid in being partially if not solely responsible for the persistence of the larval condition in the hypophysis-free larvae, and conversely to suspect that the feeding of anterior lobe substance would not give. the reverse of this picture, namely, an acceleration of metamorphosis.

In feeding experiments using thyroidless and hypophysectomized larvae in which for many months the sole food of these animals, aside from a small component of lettuce, was fresh beef anterior lobe, one of us (Smith, 1918, 1920) observed no evidence of metamorphosis. Nor were the normal larvae prematurely metamorphosed in any decisive way. The hypophyseal feeding of Gudernatsch (1914) also failed to show the pronounced results reported by the Hoskins.

The question which has again been raised by the work of the Hoskins is a pertinent one. Their results would appear to be decisive, although at variance with what might logically be 
expected, as well as in direct disagreement with similar work of other investigators. It thus seems justifiable to present new evidence and perhaps throw more light upon this much vexed question of the interrelationship of the thyroid and hypophysis.

In the experiments herein detailed both normal and thyroidectomized frog larvae were used. The specimens of each of the series were from a common egg mass and only those individuals were used which had obtained a certain average size. Since the various groups composing each series contained only a comparatively small number of specimens (4-5) statistical treatment is precluded. Yet the results have been so decisive that a larger number of individuals appears unnecessary.

The aquariae used were those described in a previous paper (Smith, 1920). They were supplied with a continuous but small amount of freshly aërated sterilized water. The water supply was carefully regulated so that each container received approximately the same amount, hence avoiding a variable dilution of any hormonal or other principle contained in the rearing dishes. The special substances were supplied the groups daily, the uneaten particles and casts being removed 24 hours later. These special substances furnished the entire food supply of the larvae with the exception of a weekly contribution of ground fresh lettuce.

With the exception of the groups receiving fresh pituitary, fresh muscle and fresh liver, each group of a series received an identical amount by weight of pituitary substance at each feeding. The amounts fed proved to be in excess of the nutritional demands of the larvae.

The results reported by Hoskins and Hoskins from the feeding of the anterior lobe tablets used by them were fully confirmed by our work. Not only was metamorphosis in the normal tadpole prematurely inaugurated and greatly accelerated, but also as in the experience of these investigators metamorphosis was inaugurated in the thyroid-free tadpole by the administration of these tablets.

With equal certainty we also confirmed the results from the feeding of fresh and the dried pituitary prepared in this laboratory, Smith $(1918,1920)$. And we must also report that both Parke Davis' powder and also Armour's powder gave in general 
concordant results. ${ }^{3}$ These substances did not decisively hasten metamorphosis in the normal tadpole, nor did they induce any indication of metamorphosis in the thyroidless larvae. These results are shown in the following protocols.

SERIES II. This series was composed of nine groups of normal tadpoles, each group being composed of six specimens. These groups received respectively: (1) Parke, Davis' anterior lobe powder; (2) Armour's anterior lobe powder; (3) Armour's anterior lobe tablets; (4) anterior lobe powder prepared in this laboratory; (5) fresh beef anterior lobe; (6) powdered dried posterior lobe; (7) powdered dried muscle; (8) powdered dried liver; (9) ground fresh liver or muscle. Each group received $0.13 \mathrm{gm}$. (2 grains) of the dried substance daily. (Each anterior lobe tablet, although weighing five grains, contained but two grains of actual pituitary substance.) The fresh substances were not weighed, but were clearly in excess of the nutritional needs, as indeed was the case also with the dried foods. Measurements were taken every three days; only the following need be given:

June 25-Series started. The average total length of the specimens of the various groups was from 25 to $28 \mathrm{~mm}$. with a hind-leg length of approximately $1 \mathrm{~mm}$.

July 15-The specimens of each of the groups except those of group 3 had grown very considerably, now averaging 29 to $33 \mathrm{~mm}$., with $\dot{a}$ hind-leg length of 1.5 to $3 \mathrm{~mm}$. The specimens of group 3 averaged $25 \mathrm{~mm}$. (body $10 \mathrm{~mm}$., tail $15 \mathrm{~mm}$.) with a hind-leg length of $3 \mathrm{~mm}$. On June 25th the average length of this group had been 28 $\mathrm{mm}$. The specimens of this group were emaciated, were eating but little and cutaneous and mouth metamorphic changes were evident.

July 24-The last specimen of group 3 was dead. All these specimens showed pronounced metamorphic changes but did not develop legs of normal size nor complete the absorption of the tail. The specimens of the other groups continued to grow, averaging 32 to $36 \mathrm{~mm}$.

July 27-A ugust 23-Development continued until the series was discontinued on August 23. Exclusive of the specimens of group 3 the most rapid development took place in the specimens of groups 2 and 4 , the specimens of these two groups metamorphosing somewhat, though not decisively, earlier than those of the other groups.

SERIES III. This series was composed of five groups of thyroidectomized specimens, each group containing 4 specimens. These groups were fed respectively: (1) Armour's anterior lobe tablets; (2) dried anterior lobe prepared in this laboratory; (3) fresh anterior lobe; (4) dried muscle; (5) fresh muscle or liver. The same dosage was used as in Series II. Measurements were taken every three days.

July 1-Series started. The average length of the specimens of the various groups varied from 28.5 to $31 \mathrm{~mm}$. The hind-limb buds were just distinguishable, being about .1 to $.2 \mathrm{~mm}$. in length.

July 15-Slight growth had taken vlace in the specimens of all of the groups except those of group 1. The specimens of group 1 averaged $28 \mathrm{~mm}$. with a hind-leg length of $1.5 \mathrm{~mm}$. The specimens of the other groups averaged from 29.5 to $32 \mathrm{~mm}$. with a hind-leg length of .2 to $.4 \mathrm{~mm}$. All specimens were typical thyroidectomized larvæ.

July $24-$ The specimens of group 1 averaged $26.5 \mathrm{~mm}$. in total length, with a hind-leg length of $3.5 \mathrm{~mm}$. They appeared somewhat

3. These tablets and powders were supplied this laboratory by Armour and Company and by Parke, Davis \& Company. We wish to express our appreciation for their cooperation. 
emaciated and metamorphic cutaneous, and mouth changes were plainly evident. The specimens of the other groups averaged from 30.5 to $33 \mathrm{~mm}$., with a hind-leg length of .4 to $.6 \mathrm{~mm}$. and were typical thyroidectomized larvæ.

August 9-One specimen of group 3 died on August 4. The skin and mouth was of adult type but the absorption of the tail had not been completed. The other members of this group averaged $24 \mathrm{~mm}$. in total length, with a hind-leg length of $4.6 \mathrm{~mm}$. The mouth and skin was of adult type in every member of this group. The specimens of the other groups averaged 34 to $38 \mathrm{~mm}$. in total length, with a hind-leg length of .4 to $.7 \mathrm{~mm}$. and were typical thyroidectomized larvæ.

August 19-The specimens of group 1 averaged $19.5 \mathrm{~mm}$. in total length (body 10.6, tail 9), with hind-legs $6 \mathrm{~mm}$. in length. Three specimens had fore-legs and all were of adult shape. The specimens of the other groups averaged from 36 to $44 \mathrm{~mm}$., with hind-legs measuring from .6 to $1 \mathrm{~mm}$. They were typical thyroidectomized larvæ.

August 24-The last specimen of group 1 died on August 22. It was of adult type but the tail was not completely resorbed nor were the legs of normal young adult length. The specimens of the other groups averaged from 37 to $45 \mathrm{~mm}$., with hind-legs measuring from .6 to $1.4 \mathrm{~mm}$. They were typical thyroidectomized larvæ.

Thus the anterior lobe preparations which we have employed are separable into two classes by their ability or lack of ability to decisively stimulate metamorphosis: (1) One substance-the. only one employed by the Hoskins-afforded a pronounced metamorphic stimulus. (2) The other substances failed to alter decisively the usual developmental history of the larvae. Which effect, then, expresses most nearly the actual physiological capacity of the gland when employed in feeding experiments with the normal or thyroidless individual?

Since but one anterior lobe preparation gave a pronounced metamorphic stimulus while four preparations, including the fresh gland, failed to give this stimulus, it would appear that the substances of the last mentioned class because of their numerical majority, represent in their action the physiological eapacity of the gland when fed to the tadpole.

The problem now entered its second phase. We directed our attention to the determination of any peculiarities, other than physiological, which might be enjoyed by the single substance giving this extreme metamorphic stimulus so unique in hypophyseal feeding.

Because of the known potency of iodine in organic or inorganic form to metamorphose the tadpole (Allen 1919, Swingle 1919), thyroxin iodine being also potent in this respect (Rogoff and Marine 1916) it seemed not improbable that an 
analysis for the iodine content of these various preparations would prove suggestive.

Analyses made by Dr. E. C. Kendall showed the iodine content of three of the anterior lobe preparations to be as follows : ${ }^{4}$ Sample .1 contained $.0228 \cdot \mathrm{mg}$. of iodine per gram; sample 2 contained $.0037 \mathrm{mg}$. of iodine per gram; sample 3 contained $.1787 \mathrm{mg}$. of iodine per gram; or the iodine content of 1 was $.002 \%$ that of $2, .003 \%$ and that of $3, .0178 \%$; in other words, number 3 contained 8 times as much iodine as sample 1 and 48 times as much as sample 2. But since anterior lobe substance composed but two-fifths of sample 3 , the remaining three-fifths being milk sugar, therefore, the actual pituitary substance of this sample contained approximately 120 times as much iodine as sample 2.

Using the iodine content of sample 3 as a standard we then prepared three diets (diets $4,5,6$ ) each having the precise iodine content of sample 3 , and one check diet (diet 7). The supply from which sample 3 , above, was taken served as diet 3 . These diets were as follows.

Diet 4-"Anatomy pituitary" 2 parts, milk sugar 3 parts, to which thyroxin ${ }^{3}$ was added in sufficient amount to give an iodine content of $0.1787 \mathrm{mg}$. of iodine per $\mathrm{gm}$. (See analysis of 3.)

Diet 5-"Anatomy pituitary" to which thyroxin was added in sufficient amount to give an iodine content of $.4467 \mathrm{mg}$. of iodine per gm. (Diets 3,4 , and 6 were fed in 5 grain doses. Each group then received 2 grains of actual pituitary substance. Diet 5 was fed in 2 grain $(0.13 \mathrm{gm}$.) doses, thus to give an amount of iodine at a feeding equivalent to the other samples it needed to contain $0.4467 \mathrm{mg}$. of iodine per $\mathrm{gm}$.)

Diet 6- "Anatomy pituitary" 2 parts, milk sugar 3 parts, to which KI was added in sufficient amount to give an iodine content of $0.1787 \mathrm{mg}$. of iodine per gm.

Diet 7-"Anatomy pituitary" 2 parts, milk sugar 3 parts.

Two critical series, one composed of normal and one of thyroidectomized tadpoles, were fed with diets 3 to 7 . We wish to call special attention to the fact that each of the groups in a series contained the same number of animals and that the animals composing these groups were nearly of the same size. (See protocols of Series V and VI.) Further, each group of a series

4. Sample 1 was Armour's anterior lobe powder. Sample 2 was dried anterior lobe substance prepared in this laboratory, "Anatomy pituitary." Sample 3 was Armour's anterior lobe tablets.

5. The thyroxin was kindly supplied the laboratory in crystalline form by Dr. Kendall in 1918 . It contained $65 \%$ of iodine. 
received the same amount of dried pituitary substance and, except for the check group, the same amount of actual iodine, though in different combinations. These two series then would appear to fulfil all the essential requirements for determining. whether pituitary plus iodine in certain combinations would give the effect which the Hoskins had secured and which we had confirmed with the substance which they employed, but with no other pituitary substance.

SERIES V. This series was composed of five groups of 4 normal specimens each. These groups received respectively: (1) diet 3; (2) diet 4 ; (3) diet 5 ; (4) diet 6 ; (5) diet 7 . Each group, except 3 , received daily $0.324 \mathrm{gm}$. of its special diet; group 3 received two-fifths of this amount or $0.13 \mathrm{gm}$. daily. Thus each group received an identical amount of pituitary substance. Measurements of body, tail, and leg lengths were taken every three days.

August 27-The series was started. The specimens of the various groups averaged 38 to $40 \mathrm{~mm}$. in total length, with a hind-leg length of 4.5 to $7.5 \mathrm{~mm}$. They were typical larvæ in all respects.

September 7-The specimens of groups 1,2 , and 3 averaged 32 to $35 \mathrm{~mm}$. in total length, with a hind-leg length of 12 to $14.5 \mathrm{~mm}$. The epidermis and mouth of each were assuming the adult type, the tails in a few cases were undergoing resorption. The specimens of groups 4 and 5 averaged $40 \mathrm{~mm}$. in total length, with a hind-leg length of 8.5 to $10 \mathrm{~mm}$. All specimens were typical larvæ.

September 16 -The specimens of groups 1,2 , and 3 averaged 23 to $27 \mathrm{~mm}$. (body $13 \mathrm{~mm}$., tail $11 \mathrm{~mm}$.). The fore-legs were out in all specimens and the mouth and skin of each specimen was of adult type. The specimens of groups 4 and 5 averaged respectively 41 and $43 \mathrm{~mm}$. in total length, their hind-legs averaging $16 \mathrm{~mm}$. The fore-legs were not visible. Those of group 5 were typical larvæ; the skin and mouth of each of the specimens of group 4 showed slight metamorphic changes.

September 19-The specimens of groups 1, 2, and 3 were all adult in shape and their tails were nearly resorbed ( 4 to $8 \mathrm{~mm}$.). Two specimens of group 1, three of group 2, and one of group 3 had completed metamorphosis. The bodies of the specimens of group 4 averaged 14 mm., their tails $21 \mathrm{~mm}$. Fore-legs were out in 3 specimens. The hindlegs of all were of young adult size, the skin was of adult type, and the mouths of 2 specimens were of adult type, while 2 were of larval type. The bodies of the specimens of group 5 averaged $15 \mathrm{~mm}$., the tail $27 \mathrm{~mm}$. The hind-legs were of young adult size, the skin was. partly of adult type. One specimen had fore-legs. phosed.

September 21-All specimens of groups 1,2, and 3, had metamor-

September 26-Two specimens of group 4 metamorphosed. The bodies of the two remaining specimens measured $15 \mathrm{~mm}$, the tails 18 $\mathrm{mm}$. All were of adult shape. The bodies of the specimens of group. 5 averaged $15 \mathrm{~mm}$., their tails $27 \mathrm{~mm}$. The fore- and hind-legs, mouth and skin were of adult type.

September 29-One young adult removed from group 5.

October 2-The last specimens of groups 4 and 5 metamorphosed.

SERIES VI. This series was composed of 5 groups of 4 thyroidectomized specimens each. These groups were placed under the same 
dietary régime as those of Series V., namely: (1) received diet 3 (sample 3 ); (2) diet 4; (3) diet 5; (4) diet 6; (5) diet 7 .

August 26-The series was started. The specimens of groups 1 , 2,4 , and 5 averaged 36 to $40 \mathrm{~mm}$. in total length, with a hind-leg length of 0.3 to $0.7 \mathrm{~mm}$. (The specimens of group 3 varied greatly in: size and will not be included in the following. Their history varied. but little from that of the specimens of groups 1 and 2.)

September 11 -The specimens of the various groups averaged from $35 \mathrm{~mm}$. (group 1) to $43 \mathrm{~mm}$. (group 5), those of groups 1 and 2 : had hind-limb buds 2 to $2.5 \mathrm{~mm}$. in length, and those of groups 4 and 5 hind-limb buds of 0.5 to $0.7 \mathrm{~mm}$. All specimens were typical thyroidectomized larvæ.

September 19 -The specimens of groups 1 and 2 averaged respectively 35 and $39 \mathrm{~mm}$. with hind-legs 3 to $4 \mathrm{~mm}$. in length. Each showed distinct metamorphic changes in its skin and mouth. The specimens of groups 4 and 5 measured respectively 40 and $45 \mathrm{~mm}$. in length, with hind-limb buds 0.6 to $0.9 \mathrm{~mm}$. and were tvpical thyroidectomized larvæ.

September 29-The specimens of groups 1 and 2 averaged respectively 19 and $34 \mathrm{~mm}$. in total length, with a hind-leg length of 6 to 8 $\mathrm{mm}$. The skin and mouth of each specimen were of adult type. The members of groups 4 and 5 averaged respectively 42 and $47 \mathrm{~mm}$. in total length, with a hind-leg length of 1 to $1.4 \mathrm{~mm}$. and were thyroidectomized typical larvæ.

October 4-Two specimens of group 1 and one specimen of group 2 were nearly transformed and died the following day.

October 7-The remaining specimens of groups 1 and 2 measured respectively: body $11 \mathrm{~mm}$., tail $6 \mathrm{~mm}$., and body $15 \mathrm{~mm}$., tail $10 \mathrm{~mm}$. All had fore-legs and were adult in shape. The specimens of groups 4 and 5 averaged respectively: body $15.5 \mathrm{~mm}$., tail $27 \mathrm{~mm}$., and body $17 \mathrm{~mm}$., tail $32 \mathrm{~mm}$. They had hind-legs 0.6 to $1.2 \mathrm{~mm}$. in length, and were typical thyroidectomized larvæ.

October 13-The remaining specimens of groups 1 and 2 had transformed; they were not typical young adults, but were weak and had shorter legs than normal, especially the members of group 1 . The specimens of groups 4 and 5 had a typical larval shape, showed no indications of metamorphic changes and averaged respectively 45 and $51 \mathrm{~mm}$. in length, with hind-limb buds 1 to $1.3 \mathrm{~mm}$.

These two series have furnished concordant and decisive testimony as to the action of these thyroid-pituitary or iodinepituitary substances. The specimens of the groups receiving anterior lobe plus inorganic iodine paralleled very closely in development and growth their fellows supplied with a diet of anterior lobe only. And we would recall at this point that no decisive deviation resulted from the administration of our dried anterior lobe substance when carefully checked by diets of fresh anterior lobe substance-and fresh and dried muscle. Very different results were obtained with the specimens of those groups receiving pituitary plus thyroxin iodine or pituitary mixed with milk sugar plus thyroxin iodine. These specimens paralleled in 
development the specimens fed with the "anterior lobe" tablets, the normal tadpoles showing a greatly accelerated metamorphosis, the thyroidectomized larvae an initiation and rapid progression of the metamorphic process.

It now only remains to discuss briefly the results which we have obtained. The interesting and suggestive findings obtained by Hoskins and Hoskins, and which indeed seemed to demonstrate clearly that the thyroid and anterior lobe afforded an identical stimulus to metamorphosis, and thus were here presumably similar in function, appear to have been secured by the administration of "anterior lobe" substance displaying a unique activity. This appears clearly to be the case since the fresh gland and the dried gland secured from three sources failed to give the effects which they report.

Further, the "anterior lobe" substance which gave this thyroid effect was unusual in the amount of iodine which it contained. It will be recalled that an analysis of this substance showed an iodine content of $0.1787 \mathrm{mg}$. per gm., thus exceeding by some 120 times the amount of iodine which the dried gland prepared in this laboratory contained. However, the iodine content of our pituitary ( $0.0037 \mathrm{mg}$. per $\mathrm{gm}$.) is as great as is usually found in anterior lobe substance, for analyses have shown no more than a trace and usually an absence of this halogen, Simpson and Hunter (1911), Denis (1911), Halliburton, Candler and Sikes (1909) and Seaman (1920).

It has repeatedly been shown that the iodine content of the thyroid gland is subject to a seasonal variation, Seidell and Fenger (1913), Fenger (1918). By analogy we might find an explanation for the high iodine content of the material used by the Hoskins if it was shown that there is likewise as great or a greater seasonal iodine variability in the anterior lobe of the pituitary.

We have attempted to ascertain whether anterior lobe substance, to which iodine in certain forms was added in amounts identical with that occurring in the "anterior lobe" tablets which gave this decisive metamorphic stimulus, would likewise give this stimulus. Inorganic iodine (KI) gave negative results, although from the conclusive work of Allen (1919) and Swingle (1918), it is certain that if used in larger amounts it would have induced 
metamorphosis. Our results in this respect are somewhat similar to those of Cameron and Carmichael (1920), who found that sodium iodide failed to give any of the metabolic effects (enlargement of heart, liver, kidneys, etc.), which they. obtained in the mammal by thyroid feeding even when the iodine was used in amounts 100 times as great as occurred in the thyroid substance used by them. We obtained positive results with iodine in the form of thyroxin iodine in amounts identical with that found in the tablets. The tadpoles supplied with this substance paralleled in development their tablet-fed brethren.

Evidence has been repeatedly advanced suggesting a vicarious relationship between the anterior lobe of the pituitary and the thyroid gland since the pioneer work of Rogowitch in 1888 . Such evidence has not clearly established such a vicarious relationship though it cannot be questioned that an inter-relationship obtains between these two glands, as indeed is the case between all the members of the endocrine system. The early removal of the pituitary leads to a striking underdevelopment of the thyroid, Adler (1914), Smith (1916), Allen (1917). There can be thus no assumption of the function of the ablated gland by the thyroid under this condition. It has been assumed that the enlargement of the pituitary subsequent to thyroidectomy, which has been clearly demonstrated by Rogowitch (1888), Trautmann (1916), Rogers (1918), Hoskins and Hoskins (1919), and others, indicated that the pituitary was compensating for the loss of the thyroid. Yet the evidence does not prove that such is the case. From the physiological side the work of Simpson and Hunter (1911) is against this view, while the classical work of Trautmann (1916) shows that although there is a hypertrophy of the anterior lobe following thyroidectomy, yet this hypertrophy ultimately leads to degenerative changes. Ablation experiments thus do not supply evidence of a vicarious relationship between the anterior lobe and the thyroid. Likewise feeding experiments have failed to establish that anterior lobe feeding gives a thyroid effect, or conversely that thyroid feeding gives an hypophyseal effect.

In 1918 one of us, Smith, noted that anterior lobe feeding to the normal tadpole produced a slightly larger individual and a somewhat earlier average appearance of meta- 
morphosis and completion of the same. These effects did not exceed the normal variation and so were not decisive. In general these results have been confirmed in the present study though again they have not transcended the normal variation and so have not been decisive. Any earlier metamorphosis was not gained, however, at the expense of the size of the individual as in thyroid feeding; the effects are very dissimilar. These results secured by the administration of anterior lobe to tadpoles appear to be similar to, but not as pronounced as, the very interesting results gained by transplanting the anterior lobe into the normal, pituitaryless or thyroidless tadpole reported by Allen (1920, 1921). This investigator reports that such grafts stimulate growth but "clearly show that the anterior lobe of the hypophysis exerts an influence upon metamorphosis only indirectly through its influence upon the thyroid gland." Clearly, evidence secured from the experimental ablation, feeding, and transplantation of the anterior lobe and of the thyroid have failed to establish that a functional similarity or vicarious relationship exists between these two glands.

\section{SUMMARY}

1. We were able to confirm the results of Hoskins and Hoskins obtained by the feeding of what they supposed to be anterior lobe tablets. Tablets of this substance obtained from the same source as their material caused an acceleration of metamorphosis in the normal tadpole and induced metamorphosis in the thyroid-free larvae.

2. Fresh anterior lobe substance, dried anterior lobe prepared in this laboratory, and the dried gland from two other sources failed, on the other hand, to alter decisively the development of the normal tadpole or to induce metamorphosis in the thyroidless specimens.

3. Analyses of these two classes of anterior lobe substances revealed the fact that the substance affording a metamorphic stimulus contained $0.1787 \mathrm{mg}$. of iodine per gin. (Each gram of this substance was composed of $0.4 \mathrm{gm}$. of anterior lobe substance and $0.6 \mathrm{gm}$. of milk sugar. Thus the actual pituitary substance would supposedly have contained $0.4467 \mathrm{mg}$. of iodine per gm.) The dried anterior lobe substances prepared in this labora- 
tory contained approximately $1 / 120$ of this amount of iodine, or $0.0037 \mathrm{mg}$. per gm.

4. Normal and thyroidectomized tadpoles fed upon the dried anterior lobe substance prepared in this laboratory, to which sufficient iodine in the form of KI to give an iodine content of $0.4467 \mathrm{mg}$. per gm. was added, nearly paralleled in development the tadpoles receiving the fresh gland and the untreated dried gland. On the other hand, normal and thyroidectomized tadpoles fed upon the dried anterior lobe substance prepared in this laboratory, to which sufficient iodine in the form of thyroxin iodine was added to give an iodine content of $0.4467 \mathrm{mg}$. per gm., exhibited a rapid rate of metamorphosis, paralleling in their development the tadpoles mentioned in paragraph 1 of the Summary.

\section{LITERATURE CITED}

Adler (I.): Metamorphosestudien an Betrachierlarven. Arch. $f$. Entwcklngsmeehn. (Berl.), 1914, 39, 21-45.

Allen (B. M.): Effects of the extirpation of the anterior lobe of the hypophysis of Rana pipiens. Biol. Bull. (Woods Hole), 1917, 32, 117-130.

Allen (B. M.): The relation of the pituitary and thyroid glands of Bufo and Rana to lodine and metamorphosis. Biol. Bull. (Woods Hole), $1919, \mathbf{3 6}$.

Allen (B. M.): Experiments in the transplantation of the hypophysis of adult Rana pipiens to tadpoles. Science (Garrison, N. Y.), N. S., 1920, 52, $274-276$.

Allen (B. M.): The effects of transplantation of the several parts of the adult hypophysis into tadpoles in Rana pipiens. Proc. Am. Soc. Zool., Anat. Rec. (Phila.), 1921, 20, 192-193.

Cameron (A.T.) \& Carmichael (J.): Contributions to the biochemistry of iodine. III. The comparative effects of thyroid and iodide feeding on growth in white rats and in rabbits. J. Biol. Chem. (Balt.), 1920, 45, 69-100.

Denis ( $W_{.}$): A note regarding the presence of iodine in the human pituitary. J. Biol. Chem. (Balt.), 1911. 0, 363-364.

Fenger (F.): On the seasonal variations in the iodine content of the thyroid gland. Endocrinology (Los Angeles), 1918, 2, 98-100.

Graham (A.): A study of the physiological activity of adenomata of the thyroid gland, in relation to their iodine content, as evidenced by feeding, experiments on tadpoles. Jour. Exp. M. (Balt.), 1916, 24, 345-359.

Gudernatsch (J. F.): Feeding experiments on tadpoles. Am. Jour. Anat. (Phila.), 1914, 15, 431-480.

Halliburton (W. D.), Candler (J. P.) \& Sikes (A. W.): The human pituitary body. Quart. Jour. Exp. Physiol. (Lond.) 1909, 2, 229-242.

Hoskins (E. R.) \& Hoskins (M. M.): Growth and development of amphibia as affected by thyroidectomy. Jour. Exp. Zool. (Phila.), 1919, 28, 1 -69.

Hoskins (E. R.) \& Hoskins (M. M.): The inter-relation of the thyreoid and hypophysis in the growth and development of frog larvae. Endocrinology (Los Angeles), 1920, 4, 1-32.

I.enhart (C. H.): The influence upon tadpoles of feeding desiccated thyroid gland in variable amounts and of variable iodine contents. Jour. Exp. M. (Balt.), 1915, 22, 739-746.

Morse (M.): The effective principle in thyroid accelerating involution in frog larvae. J. Biol. Chem. (Balt.), 1914, 10, 421-429.

Rogers (J. B.): The effect of the extirpation of the thyroid upon the thymus and the pituitary glands of Rana pipiens. Jour. Exp. Zool. (Phila.), 1918, 24, 589-605.

Rogoff (J. M.) \& Marine (D.): Effect on tadpoles of feeding products obtained by alkaline hydrolysis. J. Pharm. \& Exp. Therap. (Balt.), $1916,8,57-73$. 
Rogowitch (N.): Sur les effets de l'ablation du corps thyroide chez les animaux. Arch. de Physiol. (Paris), 1888, Série 4, 2, 419-467.

Seaman (E. C.): Note on the presence of iodine in large quantities of sheep pituitary gland. J. Biol. Chem. (Balt.), 1920, 43, 1-2.

Seidell (A) \& Fenger (F.): Seasonal variation in the iodine content of the thyroid gland. J. Biol. Chem. (Balt.), 1913, 13, 517-526.

Simpson (S.) \& Hunter (A.): The possible vicarious relationship between the pituitary and thyroid glands. Quart. Jour. Exp. Physiol. (Lond.), 1911, 4, 257-272.

Smith (P. E.): The effect of hypophysectomy in the early embryo upon the growth and development of the frog. Anat. Rec. (Phila.), 1916, 11., $57-64$.

Smith (P. E.): The growth of normal and hypophysectomized tadpoles as influenced by endocrine diets. Univ. Cal. Pub. in Physiol. (Berkeley), 1918, 5, 11-22.

Smith (P. E.): The pigmentary, growth and endocrine disturbances induced in the anuran tadpole by the early ablation of the pars buccalls of the hypophysis. Amer. Anat. Mem. (Phila.), 1920, No. 11.

Swingle (W. W.): Iodin as the active principle of the thyroid gland. Endocrinology (Los Angeles), 1918, 2, 283-288.

Swingle (W. W.): Studies on the relation of iodin to the thyroid. Jour. Exp. Zool. (Phila.), 1919, 27, 397-415.

Trautmann (A.): Hypophyse und Thyreoidektomie. Frankfurter Ztschr. f. Path., 1916, 80, 173-305. 